\title{
Hypothermia during sports swimming in water below $11^{\circ} \mathrm{C}$
}

Division of Basic Medical Sciences, St. Bartholomew's and The Royal London School of Medicine and Dentistry, Queen Mary and Westfield College, University of London, London, UK W R Keatinge

Moscow Regional Centre for Human Adaptation to Extreme Conditions of Water Immersion, Moscow, Russia

M Khartchenko

N Lando

V Lioutov

Correspondence to: Professor W R Keatinge, Division of Basic Medical Sciences, Queen Mary and Westfield College, Mile End Rd, London E1 4NS, UK w.r.keatinge@qmw.ac.uk

Accepted 22 June 2001
W R Keatinge, M Khartchenko, N Lando, V Lioutov

\begin{abstract}
Objectives-To assess precautions needed to avoid dangerous hypothermia in endurance sports swims in water below $11^{\circ} \mathrm{C}$, using rectal temperature, anthropometric measurements, and voluntary swim times during a six day marathon relay swim. Methods-The time in the water and the decrease in rectal temperature were measured during the longest of three to five relay swims by each of eight experienced swimmers in $9.4-11.0^{\circ} \mathrm{C}$ water. Height, weight, and four skinfold thicknesses were measured.

Results-Swimmers with less subcutaneous fat terminated their swims after significantly less time in the water than those with thicker skinfold thickness, even though their rectal temperatures were not significantly lower. The lowest rectal temperature recorded was $34.3^{\circ} \mathrm{C}$.

Conclusions-Subjective sensation in these experienced swimmers gave reliable guidance on safe durations for swims, and all voluntarily left the water with rectal temperatures that present no threat to people able to rewarm in safe surroundings. Endurance swims in highly competitive conditions or water below $9^{\circ} \mathrm{C}$ may require continuous temperature monitoring for safety.

(Br F Sports Med 2001;35:352-353)
\end{abstract}

Keywords: hypothermia; swimming; fat thickness

Sports swims of various durations in water at and below $11^{\circ} \mathrm{C}$ are increasingly common. An annual international championship of ice water swimming, with brief swims in artificial holes in the sea ice off Helsinki, was started in February 2000. People have been immersed without harm in water at $5-11^{\circ} \mathrm{C}$ for as long as five hours. ${ }^{1-4}$ However, there are anecdotal accounts of at least two deaths, probably from hypothermia, during long distance sports swims in seas near Britain. People vary greatly in their rate of body cooling in cold water. Subcutaneous fat is an important factor retarding body heat loss in cold water. ${ }^{3}$ Large differences in surface area/mass ratio, assessed as $\mathrm{W}^{0.425} \times$ $\mathrm{H}^{0.725} \times 0.07184$ where $\mathrm{H}$ is height $(\mathrm{cm})$ and $\mathrm{W}$ is weight $(\mathrm{kg})$, can also affect the rate of body cooling. ${ }^{5}$ We describe such measurements on marathon relay swimmers. They were made for safety and to provide information to the swimmers, but have general implications with regard to the precautions needed for endurance swims in water below $11^{\circ} \mathrm{C}$.

\section{Methods}

Eight experienced Russian cold water swimmers, aged 29-53 years, participated in a 92 $\mathrm{km}$ relay swim in Finnish lakes starting 29 May 2000 wearing one piece bathing suits (women) or trunks (men). All participants swam once daily, on five or six days of the six day event. We recorded data for the longest of three to five swims by each when water temperature was $<11^{\circ} \mathrm{C}$. Each swimmer planned in advance the approximate duration of each swim with the relay team organiser (VL) but then varied this time on the basis of sensations during the swim. After each swim, the swimmer rewarmed in a sauna on the attendant launch. Height and weight were measured for each swimmer. Skinfolds at four standard sites-over the biceps, lower corner of the scapula, costal margin below the midpoint of the clavicle, and the abdomen $50 \mathrm{~mm}$ below and lateral to the umbilicus-were measured with Harpenden calipers. Table 1 presents the mean of the skinfold measures for each swimmer. Rectal temperature was measured at $120 \mathrm{~mm}$, and recorded in resting conditions in the cabin of
Table 1 Data from longest swim by each swimmer in water $\geqslant 11^{\circ} \mathrm{C}$

\begin{tabular}{|c|c|c|c|c|c|c|c|c|c|}
\hline \multirow[b]{2}{*}{ Swimmer } & \multirow[b]{2}{*}{$M / F$} & \multirow[b]{2}{*}{ Age (years) } & \multirow{2}{*}{$\begin{array}{l}\text { Skinfold } \\
\text { thickness } \\
(\mathrm{mm})^{\star}\end{array}$} & \multirow[b]{2}{*}{ Height (m) } & \multirow[b]{2}{*}{ Weight $(\mathrm{kg})$} & \multirow[b]{2}{*}{$\begin{array}{l}\text { Water temp } \\
\left({ }^{\circ} \mathrm{C}\right)\end{array}$} & \multirow[b]{2}{*}{$\begin{array}{l}\text { Duration of } \\
\text { swim (min) }\end{array}$} & \multicolumn{2}{|c|}{ Rectal temp $\left({ }^{\circ} C\right)$} \\
\hline & & & & & & & & $\begin{array}{l}\text { Fall during } \\
\text { swim }\end{array}$ & $\begin{array}{l}\text { Temp after } \\
\text { swim }\end{array}$ \\
\hline 1 & M & 53 & 8.56 & 1.78 & 76.0 & 11.0 & 23 & 2.9 & 34.3 \\
\hline 2 & $\mathrm{~F}$ & 29 & 8.61 & 1.77 & 72.0 & 10.0 & 45 & 2.3 & 34.7 \\
\hline 3 & $\mathrm{~F}$ & 41 & 8.90 & 1.62 & 60.0 & 10.0 & 49 & 1.6 & 35.6 \\
\hline 4 & M & 42 & 12.18 & 1.81 & 82.0 & 9.4 & 32 & 1.6 & 35.9 \\
\hline 5 & M & 36 & 13.40 & 1.80 & 81.5 & 10.5 & 66 & 1.7 & 36.1 \\
\hline 6 & $\mathrm{~F}$ & 29 & 17.55 & 1.71 & 81.5 & 10.2 & 73 & 0.7 & 36.5 \\
\hline 7 & M & 47 & 18.41 & 1.76 & 90.0 & 10.2 & 65 & 2.7 & 34.8 \\
\hline 8 & M & 41 & 21.50 & 1.80 & 102.5 & 10.0 & 65 & 2.0 & 36.0 \\
\hline Mean & & 39.8 & 13.64 & 1.76 & 80.7 & 10.2 & $52.3 \dagger$ & 1.94 & 35.5 \\
\hline
\end{tabular}

${ }^{\star}$ Mean of readings by Harpenden calipers over biceps, lower corner of the scapula, the costal margin below the midpoint of the clavicle, and the abdomen $50 \mathrm{~mm}$ below and lateral to the umbilicus.

†Related to mean skinfold thickness, $\mathrm{p}=0.035$ (least squares linear regression). 
the launch in air at $18-25^{\circ} \mathrm{C}$ before swims and at its coldest point in the afterdrop 6-25 minutes after the swims.

\section{Results}

Mean skinfold thickness varied between 8.56 and $21.5 \mathrm{~mm}$ (table 1 ). Surface area/mass ratio of the swimmers varied only between 0.022 and $0.027 \mathrm{~m}^{2} / \mathrm{kg}$ and is not reported in detail.

Table 1 shows that people with less thick subcutaneous fat made significantly shorter swims than those with thicker fat layers $(\mathrm{p}=$ $0.035)$. The thinnest subject swam for only 23 minutes, whereas the four with the thickest fat layers swam for over an hour. The leanest swimmer had the largest fall in rectal temperature, $2.9^{\circ} \mathrm{C}$, and the lowest rectal temperature after the swim, $34.3^{\circ} \mathrm{C}$, but, overall, the falls were not significantly related to fat thickness.

\section{Discussion}

The data imply that the thinner swimmers largely compensated for faster heat loss by shorter swims, and were able to judge when it was necessary to leave the water as their core temperature fell to near an unacceptable level. Three swimmers cooled below $35^{\circ} \mathrm{C}$, the accepted upper limit of hypothermia, but even the lowest core temperature recorded, $34.3^{\circ} \mathrm{C}$, represents no threat to life in people able to rewarm in quiet surroundings. Self selection among these experienced cold water swimmers is likely to account for the absence of any very thin people, who would be subject to rapid cooling.

The results do imply risks if highly competitive conditions had caused them to prolong the swims. Body temperatures below $32^{\circ} \mathrm{C}^{6}$ cause a progressive risk of spontaneous ventricular fibrillation and death, and the coldest swimmer would have reached that level within about a further 20 minutes if the rate of cooling had continued. Colder water must also increase the risk, both because of faster body cooling and because pain followed by anaesthesia of the skin in very cold water could disturb ability to assess body cooling. In the $3.5^{\circ} \mathrm{C}$ water of Lake Baikal, a man who swam for 25 minutes had a rectal temperature of $32.2^{\circ} \mathrm{C}$ on leaving the water, and rewarmed without apparent harm (N Lando, unpublished work). Monitoring of body core temperature by radiotelemetry ${ }^{2}$ may be needed throughout very competitive endurance swims and in any endurance swims in water colder than $9^{\circ} \mathrm{C}$. This applies particularly to swimmers who lack extensive cold water experience backed up by measurements of fat thickness and rectal temperature.

\section{CONCLUSIONS}

Experienced cold water swimmers under experienced supervision and without competitive pressure could safely make prolonged swims in water at $9-11^{\circ} \mathrm{C}$, judging the duration of their swims only by subjective sensation.

Contributors: all authors participated in planning and making the observations, and in drafting the paper. VL organised the swim.

1 Keatinge WR, Coleshaw SRK, Millard CE, et al. Exceptional case of survival in cold water. BMf 1986;292:171-2. Keatinge WR, Nyboer J. Body temperature during a 125 -minute swim in Bering Straits in water at $7.2-7.4^{\circ} \mathrm{C} . \mathcal{f}$ Physiol (Lond) 1989;412:42P.

3 Cannon P, Keatinge WR. The metabolic rate and heat loss of fat and thin men in heat balance in cold and warm water. f Physiol (Lond) 1960;154:329-44.

4 Tipton M, Eglin C, Gennser M, et al. Immersion deaths and deterioration in swimming performance in cold water. Lancet 1999;354:626-9.

5 Sloan REG, Keatinge WR. Cooling rates of young people swimming in cold water. F Appl Physiol 1973;35;371-5.

6 Collins KJ. Hypothermia: the facts. Oxford: Oxford University Press, 1983:38.

\section{Take home message}

Experienced swimmers during a marathon relay in water at $9-11^{\circ} \mathrm{C}$ were able to assess subjectively when to leave the water as the body temperature approached hazardous levels, but could not be expected to do so if conditions had been very competitive or in endurance swims in colder water. Temperature monitoring by radiotelemetry would then provide the only assurance of safety. 